\title{
The impact of sleep loss on hippocampal function
}

\author{
Toni-Moi Prince ${ }^{1,3}$ and Ted Abel ${ }^{2,3}$ \\ ${ }^{1}$ Neuroscience Graduate Group, University of Pennsylvania, Philadelphia, Pennsylvania 19104, USA; ${ }^{2}$ Department of Biology, \\ University of Pennsylvania, Philadelphia, Pennsylvania 19104, USA
}

\begin{abstract}
Hippocampal cellular and molecular processes critical for memory consolidation are affected by the amount and quality of sleep attained. Questions remain with regard to how sleep enhances memory, what parameters of sleep after learning are optimal for memory consolidation, and what underlying hippocampal molecular players are targeted by sleep deprivation to impair memory consolidation and plasticity. In this review, we address these topics with a focus on the detrimental effects of post-learning sleep deprivation on memory consolidation. Obtaining adequate sleep is challenging in a society that values "work around the clock." Therefore, the development of interventions to combat the negative cognitive effects of sleep deprivation is key. However, there are a limited number of therapeutics that are able to enhance cognition in the face of insufficient sleep. The identification of molecular pathways implicated in the deleterious effects of sleep deprivation on memory could potentially yield new targets for the development of more effective drugs.
\end{abstract}

Chronic sleep loss is a widespread problem in our society (Strine and Chapman 2005). According to the Center for Disease Control, $\sim 7 \%-19 \%$ of adults in the US report inadequate sleep, and an estimated 50-70 million Americans suffer from chronic sleep disorders. Insufficient sleep is comorbid with chronic problems such as heart disease, kidney disease, high blood pressure, diabetes, obesity, and mental illness (Ford 1989; Gillin 1998; Knutson and Van Cauter 2008; Hirotsu et al. 2010; Vijayan 2012; Engeda et al. 2013; Najafian et al. 2013; Palagini et al. 2013). Sleep loss also contributes to irritability, aggression, inattentiveness, and diminished psychomotor vigilance (Rajaratnam and Arendt 2001; Van Dongen et al. 2003; Kamphuis et al. 2012). The negative impact of sleep loss on physical and mental health places a strain on our healthcare system (Kapur et al. 2002) and a large financial burden on our economy (Durmer and Dinges 2009). Unfortunately, the common myth is that people can function on little sleep with no consequences, even though studies employing both human and animal models demonstrate that mental and physical health requires sufficient sleep (Banks and Dinges 2007). Because so many people are unable to obtain sufficient sleep on a daily basis, it is critical to understand the molecular and cellular impact of sleep loss in an effort to identify novel therapeutic approaches to counteract these effects.

In this review, we bridge what is known about critical periods of molecular signaling post-learning with our understanding of the role of sleep in memory consolidation. This is followed by a discussion focusing on the time windows when sleep deprivation can disrupt hippocampal function. Finally, we discuss molecular targets of sleep deprivation (see Fig. 1 for a schematic overview).

\section{Molecular signaling consolidates memory}

Memory consists of at least three stages: encoding, consolidation, and retrieval. Each phase requires specific molecular machinery (Abel and Lattal 2001). Because the focus of this review is memory

\footnotetext{
${ }^{3}$ Corresponding authors
}

E-mail tprince@mail.med.upenn.edu

E-mail abele@sas.upenn.edu

Article is online at http://www.learnmem.org/cgi/doi/10.1101//m.031674.113. consolidation, we elaborate on the molecular signaling underlying this stage of memory processing, termed synaptic consolidation (Dudai 2004). A large body of work suggests that sleep is particularly beneficial to the consolidation stage of memory storage, and that this stage is vulnerable to sleep manipulation (Sagales and Domino 1973; Buzsáki 1998; Stickgold et al. 2000; Graves et al. 2003). Learning induces a transient increase in calcium $\left(\mathrm{Ca}^{2+}\right)$ and adenylyl cyclase, an enzyme responsible for production of the second messenger, cyclic adenosine monophosphate (cAMP) (Xia and Storm 2012). cAMP activates three downstream targets important for protein synthesis and eventual memory consolidation. These targets include protein kinase A (PKA), exchange protein activated by cAMP, and hyperpolarization-activated cyclic nucleotide-gated channels (Arnsten 2007). Activation of these downstream targets, along with other kinases such as calmodulin-dependent protein kinase (CAMKII), mitogen activated protein kinase, and extracellular signal-regulated kinase (ERK1/ 2), leads to phosphorylation of transcription factors (Enslen et al. 1994; Matthews et al. 1994; Roberson et al. 1999; Ahmed and Frey 2005). Transcription factors, such as cAMP response element binding protein (CREB), promote up-regulation of gene expression for proteins that will consolidate labile memories into long-term memories (Roberson et al. 1999; Roberson and Sweatt 1999). Previous time-course studies identified time windows where inhibition of these signaling components in the hippocampus impairs memory consolidation. Two periods for activation of cAMP downstream signaling and protein synthesis, immediately after learning and $4 \mathrm{~h}$ after learning, are required for consolidation (Grecksch and Matthies 1980; Bourtchouladze et al. 1998). Three peaks in cAMP levels have also been observed after training at $0.5 \mathrm{~h}, 3 \mathrm{~h}$, and $6 \mathrm{~h}$ during consolidation (Bernabeu et al. 1997). Two early sensitive periods during consolidation also exist for mRNA synthesis, ERK1/2 activity, and phosphorylation of CREB (Igaz et al. 2002; Trifilieff et al. 2006). These critical signaling periods appear to occur within the first few hours of sleep postlearning (Graves et al. 2001; Hernandez and Abel 2011). When sleep loss overlaps with these critical time windows for molecular signaling, consolidation is impaired (Smith and Rose 1996; Graves et al. 2003; Palchykova et al. 2006). These sensitive periods of molecular signaling give an approximation of when sleep deprivation could impair memory through disruption of molecular signaling processes. 


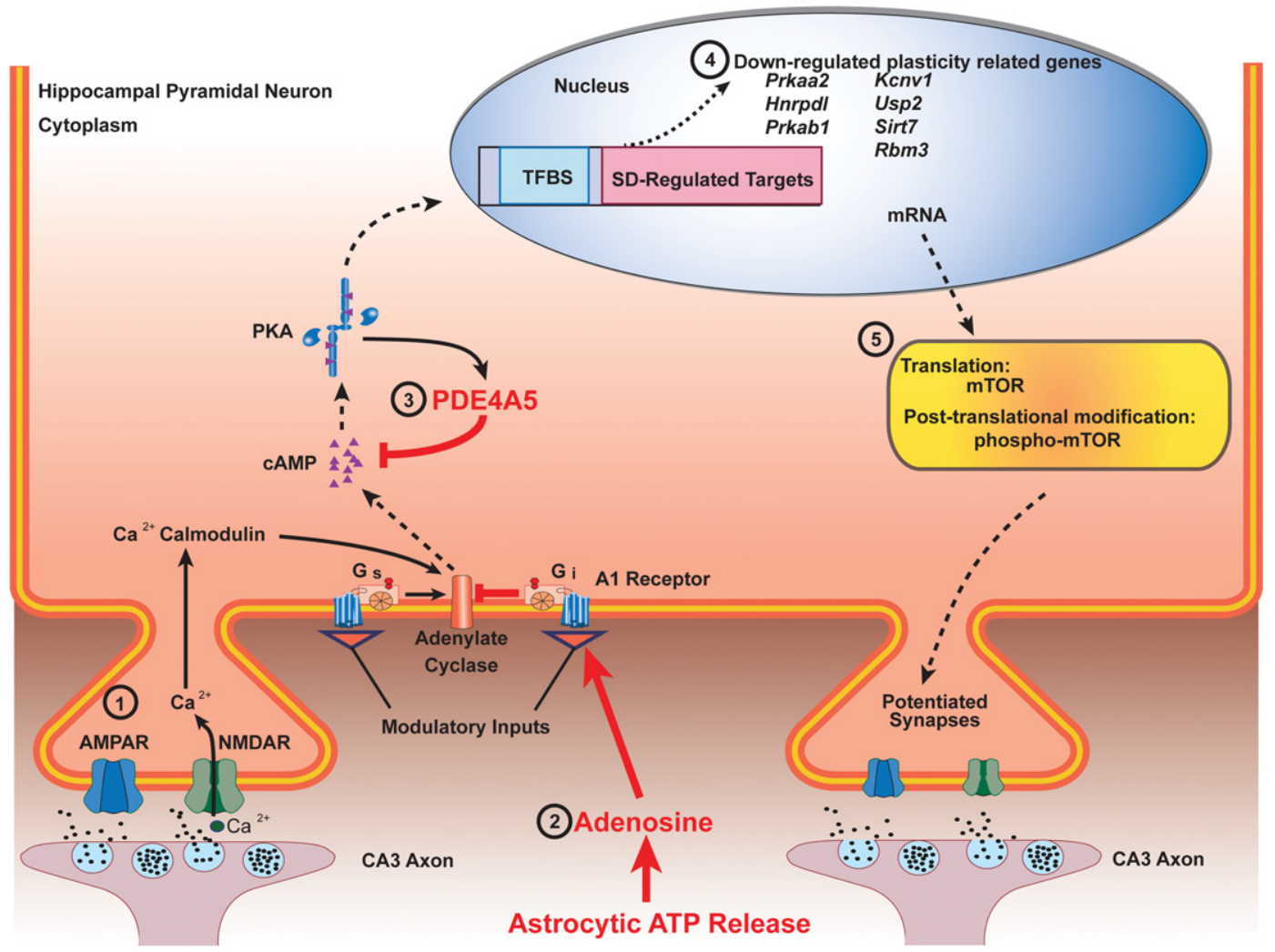

Figure 1. A schematic overview of hippocampal signaling pathways following sleep deprivation. Studies suggest multiple mechanisms by which sleep deprivation disrupts memory consolidation. (1) Sleep deprivation modulates glutamatergic signaling through alterations in NMDA and AMPA receptor subunit composition. This disruption in receptor function attenuates molecular signaling cascades through reduced calcium influx. (2) Sleep deprivation raises extracellular adenosine, an endogenous sleep factor, and astrocytes are one source of adenosine. Adenosine acts through the adenonsine A1 receptor to reduce plasticity by enhancing the inhibitory tone in the hippocampus. (3) Elevation of phosphodiesterase 4A by sleep deprivation perturbs CAMP intracellular signaling. (4) Sleep deprivation decreases transcription of plasticity related genes. (5) Sleep deprivation down-regulates mammalian target of rapamycin (mTOR) signaling, a key regulator of protein synthesis required for memory consolidation. Red arrows indicate an increase of the signaling pathway. Red font indicates an increase of activity. Dashed black arrows indicate an attenuation of the signaling pathway. Adapted from Hernandez and Abel (2011) with permission from Elsevier.

\section{Distinction between sleep states}

To discuss the consequences of sleep or sleep loss on memory, it is crucial to understand the pattern of neuronal electrical activity that occurs during different sleep states. Sleep is measured by polysomnographic recordings that combine electroencephalography (EEG), electro-oculogram (EOG), and electromyography (EMG) to distinguish the stages of sleep (Franken et al. 1991b). Sleep cycles between nonrapid eye movement (NREM) and rapid eye movement (REM) sleep (Stickgold 1998). In humans, NREM sleep can further be dissected into four stages. Rechtschaffen and Kales (1968) developed the standard scoring guidelines to determine sleep stage in humans. Rolling eye movements are prominent during stage 1 sleep, while slow oscillations, fast sleep spindles (12-15 $\mathrm{Hz}$ ), and K-complexes are prominent during stage 2. Recordings during stages 3 and 4 of NREM sleep, termed slow wave sleep (SWS), are characterized by high amplitude, low-frequency $\delta$ waves (also known as slow waves, 1-4 Hz) and spindle activity (Mölle et al. 2011). NREM sleep is accompanied by decreased muscle tone as assessed by EMG recordings (Steriade et al. 1993a, b). REM sleep EEG exhibits features similar to wake EEG with cortical activation characterized by low-voltage fast EEG activity (Hobson and Steriade 2011). Other common features of REM sleep include complete loss of muscle tone (atonia) (John et al. 2004) and characteristic REMs detected by EOG (Aserinsky and Kleitman 1953;
Jouvet 1962). Hippocampal theta rhythms, associated with wake, occur during REM sleep as well (Buzsáki et al. 1983; Greenstein et al. 1988). Interestingly, this oscillatory pattern can be observed in hippocampal and cortical regions during learning in spatial navigation and episodic retrieval (Klemm 1976; O'Keefe and Burgess 1999; Klimesch et al. 2001). NREM and REM sleep have been examined in depth in the context of memory to determine the contribution of each stage in the consolidation process.

Sleep patterns differ across species, and this difference needs to be taken into account when reviewing rodent sleep literature. While humans are diurnal and sleep $\sim 8 \mathrm{~h}$ per night in a monophasic pattern, rodents are nocturnal mammals that exhibit polyphasic sleep patterns. In humans, a full cycle between NREM and REM sleep takes $\sim 90$ min with a total of four to six cycles per night. Rodents' NREM-REM cycle is much shorter, lasting $\sim 10 \mathrm{~min}$ (Trachsel et al. 1991; Benington et al. 1994). Scoring rules in rodents also differ slightly from those in humans. While rodents exhibit NREM and REM sleep, NREM can be further broken down to SWS stage I and SWS stage II. SWS I is identified by the presence of sleep spindles in the cortical EEG. SWS II is identified by the presence of waves in the range of $0.1-4.0 \mathrm{~Hz}$ in the cortical EEG (Datta and Hobson 2000; Datta and Maclean 2007). Despite the differences in human and rodent sleep, the neurobiology regulating sleep/wake states is similar and much has been learned about how sleep affects memory by studying animal models. 


\section{Sleep enhances memory consolidation}

Evidence from various human and rodent studies supports the importance of sleep in learning and memory. In 1924, Jenkins and Dallenbach were the first to discover that sleep facilitates longterm memory formation. In this seminal study, human subjects displayed improved memory of nonsense syllables when they slept during the period between learning and recall (Jenkins and Dallenbach 1924). Since this pivotal discovery, termed the "sleep effect," several other research groups have replicated the finding that memory benefits from sleep (Smith 2001; Born et al. 2006; Gais et al. 2007; Oudiette et al. 2013; Stickgold and Walker 2013).

Although researchers agree that sleep is more effective than wakefulness for memory consolidation, debates have emerged as to what stage of sleep is beneficial for memory. Initially, most research groups hypothesized that REM sleep enhances memory consolidation due to its similarity to waking EEG and its increased firing of hippocampal neurons that had been active prior to sleep (Pavlides and Winson 1989). Much of the support for the role of REM sleep in memory came from animal studies that demonstrated an increase in REM sleep for brief time windows after learning (Smith 1985; Hennevin et al. 1995). The increase in REM sleep after learning has been demonstrated in cats trained in the instrumental learning paradigm (Lecas 1976). Increases in REM sleep were also observed in rabbits after handling, which led to more activity in successive open-field behavior assessment (Denenberg et al. 1977). Rodent studies also showed increases in REM sleep episodes after learning in associative fear-related learning tasks, such as the fear-conditioning paradigm and an escapable shock task (Sanford et al. 2010; Machida et al. 2013; Menz et al. 2013). REM sleep also increased in rodents after training in the Morris water maze paradigm (Smith and Rose 1996, 1997). Not only was an increase in REM sleep observed after training, but also REM sleep-related processes such as theta rhythm and pontine-wave activity were identified as important for memory consolidation in rodents trained in the two-way active avoidance task (Datta et al. 2005; Datta and O'Malley 2013). Many took these observed increases in REM sleep after conditioning as evidence that REM sleep was closely tied to enhancements in the memory process. This hypothesis was supported by rodent studies that involved REM sleep deprivation during these same REM sleep time windows, demonstrating memory impairments following these deprivation periods (Smith 1985).

Until the late 1980s, REM sleep was considered to be the critical sleep stage in memory improvement. However, later studies encountered difficulty demonstrating the importance of REM sleep alone in consolidation of memory (Siegel 2001). Human and rodent studies observed an increase in NREM sleep, and NREM-associated processes such as slow wave activity and spindle density after training (Stickgold et al. 2001; Gais et al. 2002; Huber et al. 2004; Hellman and Abel 2007). A few studies also demonstrated a NREM sleep-memory link in rodents through the discovery of neuronal reactivation, termed "replay," where the same set of hippocampal neurons previously active during spatial learning fired in the same sequence during hippocampal sharp-wave ripple (SPW-R) events that occur in NREM SWS (Wilson and McNaughton 1994; Lee and Wilson 2002; Ji and Wilson 2007; Ego-Stengel and Wilson 2010; Bendor and Wilson 2012). The role of NREM sleep in memory consolidation was further cemented by Rasch et al. (2007) who conducted a study where human subjects performed an associative task consisting of card locations paired with a particular odor. The researchers introduced these same smells during SWS, which activated neuronal replay in the hippocampus. This manipulation resulted in enhanced recall of card location the following day (Rasch et al. 2007). Spatial memory enhancement has also been observed when a trial-unique auditory cue paired with an object was re-presented during NREM sleep in humans (Rudoy et al. 2009). The presentation of the auditory cue during SWS increased activation of the medial temporal lobe and altered parahippocampal-medial prefrontal connectivity, which has traditionally been associated with declarative memory (Van Dongen et al. 2012). Not only has inducing neuronal replay during SWS been shown to enhance memory consolidation, but also SPW-R disruption impairs hippocampus-dependent memory (Girardeau et al. 2009; Nokia et al. 2012). In 2012, Nokia and colleagues demonstrated the necessity of SPW-R hippocampal events that are characteristic of SWS by disrupting SPW-R with electrical stimulation in rabbits. This manipulation impaired trace eyeblink conditioning, a hippocampus-dependent learning task (Nokia et al.2012). Other studies in humans have shown that reactivation during SWS can enhance not only spatial memory but also procedural memories, suggesting that reintroduction of cues during sleep may reactivate other brain regions as well (Antony et al. 2012; Oudiette et al. 2013). These findings validate the hypothesis that NREM SWS is important for learning and memory (Girardeau et al. 2009; Ego-Stengel and Wilson 2010).

Reports from human studies suggest that there is a dissociation between different sleep stages and the consolidation of different types of memory. In the "dual hypothesis" of sleep, NREM sleep is responsible for improvements in declarative memory consolidation, while REM sleep plays a more significant role for procedural and emotional memory consolidation (Gais and Born 2004). Declarative memory relies on the hippocampus, while procedural memory relies on striatal and cerebellar function (Squire et al. 1993; Doyon et al. 2003). Early studies demonstrated that NREM sleep improved declarative memories in humans. In the first set of studies to examine the role of NREM sleep in a declarative task, humans learned a verbal paired associates task before a sleep period known for a high percentage of NREM sleep and a low percentage of REM sleep. These subjects displayed superior memory in comparison to subjects trained before a high percentage of REM sleep (Yaroush et al. 1971; Barrett and Ekstrand 1972; Fowler et al. 1973). A later study by Plihal and Born $(1997,1999)$ found that subjects trained on a declarative task before sleep (predominantly composed of NREM sleep) and awakened $3 \mathrm{~h}$ later exhibited higher rates of retention compared to individuals trained on the same task who slept during a period known for high REM sleep composition.

While the work mentioned above demonstrates the importance of NREM sleep to declarative memory, researchers have also observed that procedural memory (a type of nondeclarative memory) benefits from REM sleep. Plihal and Born $(1997,1999)$ also examined the effects of REM sleep for procedural memory consolidation. Subjects who slept during a period dominated by REM sleep displayed more procedural memory gains than those who slept during a predominantly NREM sleep period. Although these studies established the importance of NREM sleep for declarative memory and REM sleep for procedural memory, the levels of cortisol, a stress hormone that has the ability to interfere with learning and recall (Ackermann et al. 2013; Goerke et al. 2013), differed between those who were trained right before a high period of NREM sleep and those who were trained right before a high period of REM sleep (Plihal and Born 1997, 1999). However, other studies have confirmed their findings by demonstrating this phenomenon of REM sleep-related memory enhancements after learning on various procedural tasks, including priming and visuomotor tasks (Mandai et al. 1989; Buchegger et al. 1991; Smith and Lapp 1991; Smith and Smith 2003; Wagner et al. 2003).

This "dual hypothesis" paints a simplistic picture of how a particular stage of sleep potentially benefits one type of memory, while another sleep stage mediates the consolidation of other forms of memory. However, the sleep period known for a high percentage of REM sleep also contains a high percentage of stage 2 
sleep and thus spindles. Therefore, procedural tasks could be benefiting from high spindle density, which has been associated with improvements in procedural memory, and not solely REM sleep (Tamaki et al. 2008, 2009; Rasch et al. 2009). Furthermore, other findings contradict this REM sleep-procedural memory link and NREM sleep-declarative memory link assertion. For instance, REM sleep has been shown to be important for emotional declarative memories (Wagner et al. 2001; Wagner 2002). NREM sleep has also been found to play a role in procedural tasks, further weakening the "dual hypothesis" argument (Walker et al. 2002, 2003). However, many of the procedural tasks developed for these experiments seem to require hippocampal involvement as well (Poldrack et al. 2001; Schendan et al. 2003). This hippocampal component of the task may require stages of NREM sleep to enhance procedural memory consolidation. This suggests that the design of the task matters to a great extent in order to control for activation of certain brain structures.

Clearly, the "dual hypothesis" dissociation between REM and NREM sleep in memory consolidation is more complex than the previously described straightforward examples. Other groups have posed alternative hypotheses that may account for the sleep stage-memory complexities; one such alternative is the "sequential hypothesis" (Giuditta et al. 1995). In this hypothesis, neither REM nor NREM sleep alone can account for memory consolidation, but the order of NREM and REM sleep after training as well as the transitions between NREM and REM sleep are essential for memory (Giuditta et al. 1995; Ambrosini and Giuditta 2001).

\section{Sleep deprivation disrupts memory consolidation}

Many studies have utilized sleep deprivation to examine the role of sleep in memory consolidation. Researchers have developed several techniques for sleep deprivation in rodents to assess how sleep loss impairs memory. Some of the main methods of sleep deprivation include the "rotating platform" technique, the "flower-pot" technique, gentle handling, novel object introduction, and optogenetic stimulation. Each method has associated positives and negatives and has been discussed more thoroughly previously (see Havekes et al. 2012). Sleep deprivation administered after learning disrupts the consolidation period and impairs memories (Fishbein 1971; Leconte et al. 1974; Linden et al. 1975). The hippocampus, in particular, appears to be vulnerable to this manipulation, as demonstrated in hippocampal-dependent memory tasks after sleep deprivation. The first set of experiments to demonstrate this sensitivity used the Morris water maze task, which can be configured to either a hippocampus-dependent version or a hippocampus-independent version (Morris et al. 1982). Previously sleep-deprived animals exhibited memory impairments in the hippocampus-dependent version of the task. However, sleep-deprived animals subjected to the hippocampusindependent version did not demonstrate a memory impairment (Smith and Rose 1996, 1997). This interesting dissociation between hippocampus-dependent and hippocampus-independent memory tasks was not restricted to the Morris water maze, but has been demonstrated with fear-conditioning tasks as well (LeDoux 2000). Mice that are sleep-deprived post-training exhibit memory impairments in the hippocampus-dependent configuration of this task, but not in the hippocampus-independent configuration of the task (Graves et al. 2003). Other studies examined sleep deprivation prior to learning in fear-conditioning tasks and observed similar results (Bueno et al. 1994; McDermott et al. 2003; Ruskin et al. 2004; Ruskin and LaHoste 2009). The Y-maze or T-maze is another type of dissociation task where researchers can examine the learning strategies animals employ to perform the task (Oliveira et al. 1997). This task allows researchers to assess whether sleep-deprived animals shift from employing a spatial strategy (hippocampus-dependent) to a response strategy (hippocampus-independent) (Hagewoud et al. 2010b). Daily 5-h sleep deprivation after training induced a shift from using a spatial strategy to a response strategy to navigate the maze (Hagewoud et al. 2010b). Watts et al. (2012) also demonstrated that decreased REM sleep, as well as decreased spindle-rich transition to REM sleep by a norepinephrine reuptake inhibitor, desipramine, impaired performance in a hippocampus-dependent spatial task, while REM sleep suppression actually enhanced performance in striatal-dependent configuration of the T-maze. This enhancement in striatal learning was likely due to the increased SWS that accompanied the pharmacological inhibition of REM sleep (Watts et al. 2012). These results confirm that the hippocampus is susceptible to the negative effects of insufficient sleep, especially reductions in sleep spindle density.

Studies have examined the effect of sleep deprivation during specific time windows of consolidation. Memory appears most sensitive to sleep deprivation when sleep is delayed after acquisition. However, if sleep occurs immediately after acquisition then long-term memory remains intact even if sleep is prevented at later time points, suggesting a sensitive period for sleep early during consolidation (Smith and Rose 1996; Graves et al. 2003; Gais et al. 2006; Palchykova et al. 2006). Based on rodent studies, this immediate window coincides with sensitive periods of molecular signaling, protein synthesis, and mRNA synthesis required for memory consolidation (Bernabeu et al. 1997; Bourtchouladze et al. 1998; Igaz et al. 2002; Trifilieff et al. 2006). For instance, delaying sleep for $5 \mathrm{~h}$ after acquisition impaired long-term memory in the contextual fear-condition paradigm. However, immediate sleep followed by a later 5 -h period of sleep deprivation had no effect on long-term hippocampus-dependent memory (Graves et al. 2003). This finding has also been observed within the hippocampus-dependent version of the water maze task (Smith and Rose 1997). Subgroups of animals were sleep deprived during different times after training. Delaying sleep for the first $4 \mathrm{~h}$ after training impaired memory in this task, whereas immediate sleep after learning did not impair memory (Smith and Rose 1997). The effect of immediate versus delayed sleep after acquisition was also examined using the novel object recognition task (Palchykova et al. 2006). The beneficial effect of immediate sleep on memory has also been documented in humans performing a hippocampus-dependent declarative memory task (Gais et al. 2006). In a study by Gais et al. (2006), one group was allowed immediate sleep after task acquisition at night, while sleep was delayed in the other group. Delaying sleep after task acquisition impaired performance in this task (Gais et al. 2006). These findings suggest the existence of a critical period for sleep deprivation to disrupt memory formation. This period occurs immediately after acquisition, and overlaps with molecular signaling-sensitive time windows during the consolidation period.

Time of day for task training also appears to be a factor in the manifestation of memory impairments induced by sleep deprivation, which suggests a circadian aspect to the ability of sleep deprivation to impair memory. To demonstrate this point, rodents trained on a novel object recognition memory task during the light phase (rest period) and then sleep deprived for $6 \mathrm{~h}$ immediately post-training displayed memory impairments. However, sleep depriving animals did not impair memory when training and sleep deprivation occurred during the dark phase (active period) (Halassa et al. 2009; Palchykova et al. 2009). This time-of-day effect has also been observed in contextual fear conditioning. Rodents were subjected to $6 \mathrm{~h}$ of post-training sleep deprivation either during the light phase or dark phase. Only the group subjected to 6-h sleep deprivation during the light phase exhibited 
impaired memory for this task (Hagewoud et al. 2010c). A 12-h sleep deprivation was required during the dark phase to impair memory, suggesting that the window for consolidation is extended during the dark phase. These differences are likely related to the observed elevation in sleep pressure during the light phase (Franken et al. 1991a), which may reduce the sleep-sensitive consolidation window during the light phase.

\section{Sleep deprivation impairs hippocampal synaptic plasticity}

Sleep deprivation is detrimental to hippocampus-dependent memory. As the neural correlate of learning and memory, it is not surprising that sleep deprivation disrupts synaptic plasticity in the hippocampus as well. Long-term potentiation (LTP), a form of synaptic plasticity, is a long-lasting change in the strength of synaptic connections through the involvement of various molecular signaling cascades and, in some cases, protein synthesis (Bliss and Lomo 1973; Whitlock et al. 2006). Campbell et al. (2002) examined LTP in area CA1 in vitro after $12 \mathrm{~h}$ of total sleep deprivation, and found that the procedure inhibited induction of LTP in the hippocampus of rodents. Since this study, follow-up studies have given us an in-depth perspective on the effects of sleep deprivation on LTP. Researchers demonstrated that, similar to behavioral studies, LTP is vulnerable to total sleep deprivation, as well as to REM-specific sleep deprivation and fragmented sleep (McDermott et al. 2003; Tartar et al. 2006; Ravassard et al. 2009; Florian et al. 2011). Similar LTP deficits occurred after sleep deprivation in vivo in dentate gyrus-CA3 region (Romcy-Pereira and Pavlides 2004; Marks and Wayner 2005; Ishikawa et al. 2006; Alhaider et al. 2011). The in vivo studies demonstrated that this LTP deficit was not an artifact of slice preparation, but was a result of the influence of sleep deprivation on the intact hippocampal circuitry. The ability to induce LTP in vivo allowed researchers to investigate the effect of sleep deprivation on the maintenance phase of LTP, which exhibited impairment after total sleep deprivation and REM sleep deprivation in this paradigm (Romcy-Pereira and Pavlides 2004; Ishikawa et al. 2006). This suggests that sleep deprivation perturbs molecular signaling pathways underlying both the induction phase and the maintenance phase of LTP.

A limited number of studies have examined disrupted signaling pathways that underlie the deficit in LTP. Of those, even fewer have tried to rescue the phenotype. Work from our research group demonstrated that acute sleep deprivation by gentle handling specifically disrupted LTP requiring cAMP signaling. Our group went on to show that the LTP deficit induced by sleep deprivation could be rescued by increasing cAMP signaling (Vecsey et al. 2009). More recent work showed that LTP was resistant to sleep deprivation if extracellular adenosine was attenuated either using a pharmacological approach or a genetic approach (Alhaider et al. 2010a; Florian et al. 2011). These studies established cAMP and adenosine as playing a role in the LTP deficit caused by sleep deprivation. There are additional cellular signaling mechanisms that are also altered by sleep loss. Other studies have examined the contribution of $\mathrm{N}$-Methyl-D-aspartate (NMDA) receptor function in the impairment of LTP after sleep deprivation. An extended period of sleep deprivation for $24-72 \mathrm{~h}$ affected NMDA receptor composition and attenuated receptor function, leading to a disruption in both induction and maintenance of LTP. This LTP deficit was reversed by treatment with an NMDA receptor NR1 subunit agonist, glycine (McDermott et al. 2006). This finding suggests that disturbances in NMDA receptor function can lead to the LTP deficits observed after chronic periods of sleep deprivation.

The effects of sleep deprivation have also been examined in long-term depression (LTD), which is another form of hippocam- pal synaptic plasticity requiring signaling components different from LTP. In contrast to the attenuation of LTP by sleep deprivation, researchers have observed either no change or facilitation of LTD after sleep deprivation in the hippocampus (McDermott et al. 2003; Tadavarty et al. 2009; 2011; Yang et al. 2012). This discrepancy in the effect of sleep deprivation on LTD facilitation is likely due to experimental design differences in LTD-induction protocol as well as to different sleep-deprivation manipulations. For instance, while Tadavarty et al. (2009) used gentle handling to sleep deprive animals, allowing them to examine the circadian contribution, McDermott et al. (2003) used the multiple platform method to have a 72-h period of REM sleep deprivation. Similarly, Yang et al. (2012) examined circadian contribution along with sleep pressure on the resulting LTD. Additionally, in vitro preparations were used in earlier cases of observed LTD facilitation after sleep deprivation (Tadavarty et al. 2009, 2011). However, facilitation of LTD in vivo after sleep deprivation has recently been observed with elevated sleep pressure due to a combination of sleep deprivation and time of day, further validating the effect of sleep deprivation on LTD facilitation (Yang et al. 2012). Tadavarty et al. (2011) examined the signaling pathways underlying facilitation of LTD in response to sleep deprivation. They found increased reliance on the $\gamma$-aminobutryic acid $B\left(G_{A B A}\right)$ receptor and metabotropic glutamate $1 \alpha$ receptors, while NMDA receptors did not play a role (Tadavarty et al. 2011). This suggests that sleep deprivation has different effects on the signaling pathways underlying these two opposing forms of plasticity.

LTP induced in vitro and in vivo displays a graded sensitivity to sleep deprivation. Extended periods of sleep deprivation for 24-72 $\mathrm{h}$ appear to eliminate or reduce LTP induction in vitro (Campbell et al. 2002; McDermott et al. 2003). However, brief periods of sleep deprivation only appear to disrupt signaling underlying LTP maintenance while induction remains intact (Vecsey et al. 2009; Florian et al. 2011). No studies have specifically examined the time course of sleep deprivation to impair LTP. However, Kopp et al. (2006) have demonstrated that as little as $4 \mathrm{~h}$ of sleep deprivation can impair LTP in vitro. In terms of in vivo experiments that have examined the time course of sleep deprivation, Marks and Wayner (2005) found that 3, 6, and $9 \mathrm{~h}$ of sleep deprivation impaired LTP, demonstrating that even an acute 3 -h period of sleep deprivation is sufficient to impair synaptic plasticity. In conclusion, sleep deprivation perturbs hippocampal plasticity even after brief bouts of sleep deprivation. These studies suggest that specific disruptions in molecular signaling by sleep deprivation impair LTP, as well as related behavioral phenotypes observed. Some of the known sleep deprivation-induced changes in signaling and transcription will be discussed in the following section.

\section{Sleep deprivation disrupts hippocampal signaling and gene expression necessary for memory}

\section{Molecular targets of sleep deprivation}

Sleep deprivation disrupts multiple signaling pathways in the hippocampus in parallel that lead to plasticity and memory impairments. This section outlines some of the more well-known signaling targets sensitive to sleep loss.

\section{N-Methyl-D-aspartate (NMDA) receptor and $\alpha$-amino-3-hydroxy-5- methyl-4-isoxazolepropionic acid (AMPA) receptor}

NMDA receptor activity plays a significant role in all three stages of memory, most notably the consolidation phase where the memory advances from a labile form to a more stable permanent form (Hernandez and Abel 2011). These receptors allow the 
expression of LTP through increased influx of $\mathrm{Ca}^{2+}$ (Xia and Storm 2012). Sleep deprivation has been shown to impair proper activation of this glutamate receptor-type through altering receptor subunit composition, surface expression, and reduced $\mathrm{Ca}^{2+}$ influx (Chang et al. 2012). McDermott et al. (2006) found that prolonged sleep deprivation $(72 \mathrm{~h}$ ) reduced the NMDA/AMPA receptor ratio in CA1 pyramidal cells in response to Schaffer collateral stimulation. NMDA receptor-mediated currents from the distal dendrites of CA1 cells had reduced amplitude after sleep deprivation manipulation. This was most likely due to the reduced surface expression of NMDA receptors after sleep deprivation (McDermott et al. 2006). The same research group also observed a higher proportion of NR1 and NR2A subunits of the NMDA receptor located intracellularly compared to surface level after sleep deprivation (McDermott et al. 2006). This disruption in NMDA receptor trafficking to the cell surface and reduction in NMDA receptor-mediated current was also observed with $24 \mathrm{~h}$ of sleep deprivation (Chen et al. 2006). Other groups have also observed decreases in NR1 protein expression in the hippocampus after sleep deprivation, supporting the hypothesis that the NMDA receptor is an important molecular target for sleep deprivation (Ravassard et al. 2009; Chang et al. 2012). NR1 subunit decrease was accompanied by synaptic plasticity and memory deficits that could be rescued with pharmacological treatment of glycine, an NR1 agonist (McDermott et al. 2003; Chen et al. 2006). The NR2B subunit of the NMDA receptor has also been observed to decrease in the hippocampus as a result of REM sleep deprivation (Lopez et al. 2008; Park et al. 2012). Although both of these studies observed clear differences in trafficking and NMDA receptor-mediated current using extended periods of sleep deprivation, these findings conflict with findings from briefer periods of sleep deprivation (Vecsey et al. 2009). Using electron microscopy, Kopp and colleagues found that $4 \mathrm{~h}$ of sleep deprivation by exposure to a novel environment and introduction to new nesting material increased the NR2A/NR2B NMDA-receptor subunit ratio as well as total NR2A subunits in the hippocampus (Kopp et al. 2006; Longordo et al. 2009). This finding was correlated with a shift in the frequency needed to elicit LTD and LTP, decreasing the threshold frequency to induce LTD and increasing the threshold frequency to induce LTP. This group also observed that removal of NR2A subunits prevented the synaptic plasticity changes induced by sleep deprivation (Longordo et al. 2009). However, these differences in subunit ratios and mediated current after sleep deprivation have not been observed by other research groups. After $5 \mathrm{~h}$ of sleep deprivation by the gentle handling procedure (Ledoux et al. 1996), no difference was observed in NMDA receptor-mediated current or in the NMDA/AMPA receptor ratio in CA1 (Vecsey et al. 2009). These differences in NMDA receptor-mediated current could be attributed to sleep-deprivation techniques used in these two experimental designs. In conclusion, NMDA receptor function is needed for plasticity and memory. Longer periods of sleep deprivation disrupt NMDA receptor function, impairing both plasticity and memory. Meanwhile, more acute sleep deprivation may or may not have this effect on receptor function, depending on the sleep-deprivation technique.

AMPA receptors, another class of glutamate receptors involved in learning and memory, appear to be involved in sleep homeostasis as well (Cirelli and Tononi 2000). Cortical and hippocampal AMPA receptor levels increase during waking hours and decrease over the sleeping period (Vyazovskiy et al. 2008). Although AMPA receptors appear to be under the influence of sleep homeostatic processes, sleep deprivation was previously not thought to interfere with hippocampal AMPA receptor function (McDermott et al. 2006). However, more recent studies showed that sleep deprivation modulated the function and efficacy of AMPA receptors in both the cortex and hippocampus.
Ravassard et al. (2009) observed that multiple days of REM sleep deprivation reduced AMPA receptor function in the hippocampus. Specifically, they found decreased protein expression of the AMPA receptor GluA1 subunit as a result of sleep deprivation (Ravassard et al. 2009). Other work has shown similar results, finding a reduction in GluA1 in the hippocampus after REM sleep deprivation (Lopez et al. 2008). This subunit in particular has been linked to spatial memory (Schmitt et al. 2005), suggesting that reduced GluA1 expression due to sleep deprivation could possibly explain the impaired spatial memory. To further assess this subunit in sleep deprivation, Hagewoud et al. (2010a) examined the effect of a 12-h sleep deprivation period on total hippocampal GluA1 protein expression and phosphorylation of GluA1-serine 845 site, an important step for incorporation of the receptor into the membrane. In this study, $12 \mathrm{~h}$ of sleep deprivation did not decrease total protein levels of hippocampal GluA1; however, this sleep deprivation manipulation decreased phosphorylation of the serine 845 site (Hagewoud et al. 2010a). Although these studies demonstrated reduced AMPA receptor function, other contradictory findings from Vyazovskiy et al. (2008) observed increased levels of total GluA1 in the hippocampus and cortex after enforced wakefulness. This difference could be a result of animal strain. In their study, they chose to use the Wistar Kyoto rat strain that is a well-known genetic animal model of depression (Vyazovskiy et al. 2008). This may have confounded their study because short-term sleep loss has been shown to improve symptoms of depression and increase hippocampal neurogenesis (Grassi Zucconi et al. 2006). Overall, there is a disruption in AMPA receptor function after sleep deprivation due to either altered protein expression of GluA1 or, in some cases, reduced phosphorylation of a site on GluA1 necessary for AMPA receptor membrane insertion. Disruption of AMPA receptor function contributes to spatial memory deficits observed in tasks after sleep deprivation.

\section{Glutamate}

As described in the previous section, both NMDA receptors and AMPA receptors fluctuate through the sleep-wake cycle. Not surprisingly, the ligand for these receptors, glutamate, has also been implicated in sleep-wake homeostasis (Disbrow and Ruth 1984; Mukherjee et al. 2012). Limited studies have examined glutamate levels in the hippocampus following sleep deprivation. One study that examined the effects of sleep deprivation on glutamate in the hippocampus found that glutamate levels increase after sleep deprivation (Cortese et al. 2010). Of the studies that have examined effects of sleep on glutamate, most concentrate on the effects of sleep and sleep loss in the cortex. These studies have observed that glutamate in the cortex levels fluctuate progressively through sleep/wake states (Jasper et al. 1965; Lopez-Rodriguez et al. 2007). Few have examined the effects of sleep deprivation on cortical glutamate levels. Bettendorff et al. (1996) found that after 12-24 h of REM sleep deprivation glutamate levels increased. Contradicting these findings, Wang and $\mathrm{Li}$ (2002) found that $96 \mathrm{~h}$ of REM sleep deprivation did not affect glutamate levels in the cortex. While these studies used microdialysis to obtain glutamate measurements, another study using in vivo amperometry observed increased glutamate levels in cortical areas during extended wakefulness and during REM sleep as well as decreased glutamate levels during SWS (Dash et al. 2009). These findings become more complex as previous sleep-wake history of the animals also factors into these results. Dash et al. (2009) also examined the effects of sleep deprivation on cortical glutamate levels. Initially, if the animal was sleep deprived, glutamate levels increased in the first hour of sleep deprivation. However, as the sleep deprivation continued, glutamate levels declined after $3 \mathrm{~h}$. During this period of declining glutamate, attempts to sleep were the highest (Dash et al. 2009). 


\section{CAMP-PKA-PDE4}

Hippocampal activation of cAMP and PKA signaling are known to be important for memory consolidation, as previously discussed in the "Molecular signaling consolidates memory" section. Both of these molecular targets have also previously been implicated in sleep processes (Graves et al. 2001; Hendricks et al. 2001; Hellman et al. 2010; Luo et al. 2013). Sleep deprivation interferes with this hippocampal signaling pathway in electrophysiology studies (Vecsey et al. 2009). The observation that shorter periods of sleep deprivation disrupt LTP maintenance suggested that sleep deprivation perturbs signaling pathways specific to the maintenance phase of LTP (Romcy-Pereira and Pavlides 2004; Vecsey et al. 2009; Florian et al. 2011). Vecsey et al. (2009) examined molecular signaling required for late-phase LTP maintenance and observed that brief sleep deprivation reduced both cAMP and PKA activity.

As a result of cAMP and PKA disruption by sleep deprivation, hippocampal downstream targets in this pathway are also perturbed. For instance, the aforementioned phosphorylation of serine 845 in the AMPA receptor subunit GluA1 by PKA has been shown to be altered in three studies examining the contribution of sleep deprivation to molecular signaling (Vyazovskiy et al. 2008; Ravassard et al. 2009; Hagewoud et al. 2010a). Interestingly, while moderate-to-chronic sleep deprivation reduced phosphorylation of serine 845 (Ravassard et al. 2009; Hagewoud et al. 2010a), Vyazovskiy et al. (2008) found an increase in phosphorylation of serine 845 after $4 \mathrm{~h}$ of enforced wakefulness. This difference could be due to both the length of sleep deprivation as well as the sleepdeprivation technique used in these experiments. Another downstream target in the cAMP-PKA pathway is the transcription factor CREB, which has already been described as important for memory and plasticity and is also affected by sleep deprivation. Phosphorylation of CREB by PKA at serine 133 was reduced in the hippocampus as a result of sleep deprivation (Vecsey et al. 2009; Zhao et al. 2010; Alhaider et al. 2011). Sleep deprivation decreased phosphorylation of CREB in the amygdala, a brain region that receives contextual inputs from the hippocampus, and is important for emotionally laced memories (Pinho et al. 2013). In this experiment, in contrast to the experimental design used in the study by Vecsey et al. (2009), animals were sleep deprived for 72 $\mathrm{h}$ by multiple platform method and then trained in the fearconditioning task. This extensive sleep-deprivation procedure along with fear conditioning may elevate stress, which has been shown to affect phosphorylation of CREB to a greater extent than gentle handling alone (Xu et al. 2006).

Phosphodiesterase 4 (PDE4) is the enzyme responsible for degradation of hippocampal cAMP, thereby reducing PKA activity. Vecsey et al. (2009) also found increased activity of PDE4 and protein expression of the specific PDE4 isoform, PDE4A5, after sleep deprivation. They found that blocking PDE4 signaling during sleep deprivation rescued not only LTP deficits due to sleep deprivation, but also the sleep-deprivation induced deficits in hippocampus-dependent memory consolidation. These experiments provided further evidence that the cAMP-PKA pathway and its downstream components are key targets for disruption by sleep deprivation. Moreover, rescue by PDE4 inhibition demonstrates that this molecular disruption by sleep deprivation produces the functional deficits in behavior and plasticity.

\section{Adenosine and astrocytes}

Different research groups have hypothesized that increased sleep pressure correlates with elevated adenosine tone, resulting in increased intensity of future sleep episodes (Bjorness and Greene 2009; Porkka-Heiskanen and Kalinchuk 2011). Adenosine is a key neuromodulator highly implicated in the sleep-wake litera- ture (Basheer et al. 2004). Adenosine levels are known to fluctuate throughout the day, peaking during the height of the active period and then diminishing over the animal's resting period in both the hippocampus and the neostriatum (Huston et al. 1996). This fluctuation in adenosine over the sleep-wake cycle has also been observed in the forebrain of animals (Porkka-Heiskanen 1997). Studies have observed both this natural homeostatic oscillation of adenosine as well as an increase in adenosine signaling with extended periods of wakefulness (Porkka-Heiskanen 1997; Basheer et al. 2007; Elmenhorst et al. 2007). The increase in adenosine after periods of wakefulness contributes to the increased drive for sleep. The effect of heightened sleepiness as a result of elevated adenosine levels can be reproduced by pharmacologically increasing adenosine (Porkka-Heiskanen 1997). Increased adenosine due to sleep deprivation contributes to activation of the adenosine A1 receptor, which inhibits synaptic transmission through attenuation of activity from neighboring excitatory neurons (Brundege and Dunwiddie 1996; Haas and Selbach 2000; Hargus et al. 2009). Activation of the A1 receptor also inhibits cAMP signaling through $\mathrm{G}_{\mathrm{i}}$ protein coupling, intersecting with another disrupted pathway (Haas and Selbach 2000; Fredholm et al. 2005). The actions of adenosine on the A1 receptor within the hippocampus could account for the negative contribution of sleep deprivation to memory. To examine this possibility, adenosine A1 receptors were pharmacologically inhibited with 8-cyclopentyl-1,3-dimethylxanthine (CPT) in animals sleep-deprived post-training (Halassa et al. 2009; Florian et al. 2011). CPT infusion into the hippocampus rescued memory and plasticity impairments induced by sleep deprivation (Florian et al. 2011). Blocking release of transmitters from astrocytes, an indirect source of adenosine, also rescued memory and plasticity impairments (Halassa et al. 2009). These studies support the involvement of adenosine and $\mathrm{A} 1$ receptor signaling in the negative consequences induced by sleep deprivation.

\section{Gene expression as a result of sleep deprivation}

Consolidation relies not only on signaling, but also on waves of gene expression and protein synthesis (Bourtchouladze et al. 1998; Igaz et al. 2002, 2004). As such, research groups have begun to conduct gene-expression studies to identify molecular targets of sleep deprivation. Much of the work has focused on gene expression in cortical areas after sleep deprivation. Microarray studies allow for the examination of thousands of transcripts after sleep deprivation. This has led to the identification of classes of genes whose expressions are modified by sleep deprivation in the cortex and hypothalamus (Mackiewicz et al. 2009; Wang et al. 2010). After acute periods of sleep deprivation, there is an observed upregulation of immediate early genes/transcription factors such as Arc, c-fos, BDNF, and NGFI-A in the cerebral cortex. As sleep deprivation lengthens, changes are observed in other gene classes such as heat shock proteins, molecular chaperones, growth factors, adhesion molecules, and components of presynaptic and postsynaptic neurotransmission machinery (for more in-depth reviews of gene expression changes in the cortex, see Cirelli and Tononi 2000; Tononi and Cirelli 2001; Cirelli 2002; Cirelli et al. 2006; Mackiewicz et al. 2009; Wang et al. 2010; Curie et al. 2013).

Changes in gene expression related to synaptic plasticity in the hippocampus after moderate sleep deprivation diverge from what has been observed in the cortex. Even within the hippocampus, researchers have observed conflicting results regarding gene expression after sleep deprivation. Taishi et al. (2001) found that after $8 \mathrm{~h}$ of sleep deprivation the immediate early gene Arc increased within the hippocampus, but the growth factor $B D N F$ remained unchanged. However, Guzman-Marin et al. (2006) later observed that BDNF, as well as Synapsin I, CREB, and CAMKII 
gene expression were reduced after sleep deprivation. Our group has recently examined gene-expression changes specifically within the hippocampus after sleep deprivation using genome-wide microarray assays. After $5 \mathrm{~h}$ of sleep deprivation, changes in gene expression of 533 genes, including Arc and Creb I, were observed in the hippocampus. Clusters of genes involved in particular functions were either up-regulated or down-regulated after sleep deprivation. Up-regulated clusters of genes included genes involved in GTP signaling, the unfolded protein response, nucleosome/chromatin assembly, ATP binding, positive regulation of transcription, and negative regulation of kinase activity. Down-regulated clusters of genes included genes involved in ubiquitination, translation, RNA-binding/processing, negative regulation of transcription, and cholesterol metabolism. These widespread changes in hippocampal gene expression were reversed with $2.5 \mathrm{~h}$ of recovery sleep following sleep deprivation (Vecsey et al. 2012). Longer periods of sleep deprivation have also been examined with regard to gene expression in the hippocampus using microarray analysis to explore the relationship between age, stress, depression, and sleep disruption (Conti et al. 2007; Porter et al. 2012). In these studies, selective changes in genes related to presynaptic machinery and synaptic plasticity were identified. Although sleep deprivation modulates gene expression, changes in gene expression are not always indicative of changes in protein expression (Cheval et al. 2012; Seibt et al. 2012). Vecsey et al. (2012) found reduced levels of the mammalian target of rapamycin (mTOR), the protein synthesis regulator, which suggests that protein translation is required for long-term memory formation and plasticity. Future studies are needed to more broadly examine changes in protein synthesis as well as gene transcription following sleep deprivation and sleep.

\section{Conclusion}

Within our society, working around the clock is applauded and seen as a form of dedication. It is commonly viewed as a driving force for success. Due to this mindset, sufficient sleep often falls by the wayside. One recurring theme that has surfaced from sleep research is that even minimal sleep loss contributes to less than stellar cognitive performance. Time windows exist where sleep deprivation disrupts hippocampal function. As mentioned previously, the time period most critical for memory formation appears to occur somewhere within the first $6 \mathrm{~h}$ following learning. Sleep deprivation constrained to this period after learning is sufficient to disrupt consolidation dependent on the hippocampus (Smith and Rose 1997; Graves et al. 2003; Palchykova et al. 2006). However, the exact onset and end of these windows where sleep is necessary for hippocampus-dependent memory have not been clearly defined. Identifying the temporal parameters of sleep necessary for memory consolidation will enable a better understanding of the effects of both sleep and sleep loss on memory.

In this review, we focused on the role of sleep in synaptic consolidation. Of course, many unanswered questions remain in the memory and sleep field that were not fully addressed in this review. One such topic is the role of sleep in the gradual shift from memory storage in the hippocampus to storage in neocortical circuits, termed systems consolidation (Dudai 2004; Wiltgen et al. 2004; Diekelmann and Born 2010). Cortical areas, such as the anterior cingulate cortex, prelimbic cortices, and the temporal cortex, have been implicated by previous genetic and pharmacological studies showing that retrieval of remote memories activates these brain regions, providing evidence that at some time point these areas become involved in memory storage (Frankland et al. 2004; Maviel et al. 2004). Although much has been discovered about the molecular mechanisms required for initial memory processing and synaptic consolidation, those underlying cortical- related systems consolidation remain less well characterized (Frankland et al. 2001; Cui et al. 2004). Activation of cortical regions for systems consolidation appears to occur mostly during periods of inactivity and sleep (Marshall and Born 2007). This is interesting in the realm of sleep studies because hippocampal SPW-Rs thought to occur specifically during SWS occur in coordination with neocortical unit firing, slow oscillations, and sleep spindles to strengthen memory consolidation (Peyrache et al. 2009; Mölle and Born 2011; Born and Wilhelm 2012). This suggests that NREM sleep plays a large role in incorporating memories to cortical areas. Questions arise as to whether disruption of SPW-R would prevent systems consolidation. A few research groups have observed that disruption of SPW-R during posttraining sleep deteriorates memory consolidation (Girardeau et al. 2009; Taxidis et al. 2013). Future studies will have to determine if disruption of SPW-R at later time points can affect memory consolidation once the memory is more reliant on neocortical areas.

So how do we currently counter the effects of sleep deprivation, which affects so much of the population? In terms of treatment options, development of new therapeutics is severely lacking in the ability to battle the negative cognitive effects that accompany insufficient sleep. Many of the drugs that exist have uncharacterized mechanisms of action. Caffeine, one of the most common stimulants, is still considered the top over-thecounter drug to combat tiredness. Caffeine enhances alertness by antagonism of adenosine A1 receptor and increases cAMP signaling through inhibition of phosphodiesterase (Fredholm et al. 1999; Wu et al. 2009). Chronic caffeine administration has been shown to prevent sleep loss-induced impairment of cognitive function and synaptic plasticity (Alhaider et al. 2010b). Another stimulant, modafinil, prescribed for treatment of excessive daytime sleepiness, prevents sleep-deprivation induced cognitive impairments (Moreira et al. 2010). This drug has not been as well characterized, but is thought to involve orexinergic neurons that project to many areas that regulate wakefulness (Chemelli et al. 1999; Scammell et al. 2000). Although the orexinergic system is involved in the stimulant effects of modafinil, this system is not the only pathway that modafinil works through to increase alertness and rescue cognition (Gerrard and Malcolm 2007). Other neurotransmitter systems affected by modafinil include histamine, norepinephrine, serotonin, dopamine, and $\gamma$-aminobutryic acid (GABA). The GABA neurotransmitter system has come to the forefront as a possible target for therapeutic treatment. Zolpidem (Ambien), a $\mathrm{GABA}_{\mathrm{A}}$ receptor agonist, is a drug recently assessed for its effect on sleep features and resulting hippocampus-dependent memory consolidation. This drug seemingly enhances memory consolidation by increasing sleep spindle density, and decreasing REM sleep (Mednick et al. 2013). Understanding the mechanics as well as the limitations of these drug types will provide insight into which molecular pathways play a role in sleep and memory. None of current treatment options effectively treat the underlying physiology of sleep deprivation, but instead seem to mask the issue by treating peripheral symptoms accompanying sleep loss. Other than improving and developing new pharmacotherapeutic treatments, researchers have now begun seeking alternatives to drug treatments by strengthening memory consolidation during sleep. For example, enhancing spindle activity and slow wave oscillations via external stimulation administered in synchrony with the endogenous rhythm of the brain during sleep can strengthen memory consolidation in humans and rodents (Marshall et al. 2006; Massimini et al. 2007; Vyazovskiy et al. 2009; Ngo et al. 2013). Hopefully, by identifying molecular targets and circuitry disrupted by sleep deprivation, we can develop more effective treatments for the accompanying impairments in cognition. 


\section{Acknowledgments}

We thank Dr. Robbert Havekes, Dr. Jennifer H.K. Choi, and Christopher Angelakos for input on the manuscript, and Dr. Pepe Hernandez and Dr. Jennifer H.K. Choi for help with the illustration. The research was supported by NIH (P01AG017628 to T.A.; Principal Investigator Allan Pack) and NHLBI Training in Sleep and Sleep Disorders (T32HL007953; Principal Investigator Allan Pack).

\section{References}

Abel T, Lattal KM. 2001. Molecular mechanisms of memory acquisition, consolidation and retrieval. Curr Opin Neurobiol 11: 180-187.

Ackermann S, Hartmann F, Papassotiropoulos A, De Quervain DJ-F, Rasch B. 2013. Associations between basal cortisol levels and memory retrieval in healthy young individuals. J Cogn Neurosci doi: 10.1162/ jocn_a_00440.

Ahmed T, Frey JU. 2005. Plasticity-specific phosphorylation of CaMKII, MAP-kinases and CREB during late-LTP in rat hippocampal slices in vitro. Neuropharmacology 49: 477-492.

Alhaider IA, Aleisa AM, Tran TT, Alkadhi KA. 2010a. Caffeine prevents sleep loss-induced deficits in long-term potentiation and related signaling molecules in the dentate gyrus. Eur J Neurosci 31: 1368-1376.

Alhaider IA, Aleisa AM, Tran TT, Alzoubi KH, Alkadhi KA. 2010b. Chronic caffeine treatment prevents sleep deprivation-induced impairment of cognitive function and synaptic plasticity. Sleep 33: 437-444.

Alhaider IA, Aleisa AM, Tran TT, Alkadhi KA. 2011. Sleep deprivation prevents stimulation-induced increases of levels of P-CREB and BDNF: Protection by caffeine. Mol Cell Neurosci 46: 742-751.

Ambrosini MV, Giuditta A. 2001. Learning and sleep: The sequential hypothesis. Sleep Med Rev 5: 477-490.

Antony JW, Gobel EW, O’Hare JK, Reber PJ, Paller KA. 2012. Cued memory reactivation during sleep influences skill learning. Nat Neurosci 15: $1114-1116$.

Arnsten AFT. 2007. Catecholamine and second messenger influences on prefrontal cortical networks of "representational knowledge": A rational bridge between genetics and the symptoms of mental illness. Cereb Cortex 17(Suppl 1): 6-i15.

Aserinsky E, Kleitman N. 1953. Regularly occurring periods of eye motility, and concomitant phenomena, during sleep. Science 118: 273-274.

Banks S, Dinges DF. 2007. Behavioral and physiological consequences of sleep restriction. J Clin Sleep Med 3: 519-528.

Barrett TR, Ekstrand BR. 1972. Effect of sleep on memory. 3. Controlling for time-of-day effects. J Exp Psychol 96: 321-327.

Basheer R, Strecker RE, Thakkar MM, McCarley RW. 2004. Adenosine and sleep-wake regulation. Prog Neurobiol 73: 379-396.

Basheer R, Bauer A, Elmenhorst D, Ramesh V, McCarley RW. 2007. Sleep deprivation upregulates A1 adenosine receptors in the rat basal forebrain. Neuroreport 18: 1895-1899.

Bendor D, Wilson MA. 2012. Biasing the content of hippocampal replay during sleep. Nat Neurosci 15: 1439-1444.

Benington JH, Kodali SK, Heller HC. 1994. Scoring transitions to REM sleep in rats based on the EEG phenomena of pre-REM sleep: An improved analysis of sleep structure. Sleep 17: 28-36.

Bernabeu R, Bevilaqua L, Ardenghi P, Bromberg E, Schmitz P, Bianchin M, Izquierdo I, Medina JH. 1997. Involvement of hippocampal cAMP/ cAMP-dependent protein kinase signaling pathways in a late memory consolidation phase of aversively motivated learning in rats. Proc Natl Acad Sci 94: 7041-7046.

Bettendorff L, Sallanon-Moulin M, Touret M, Wins P, Margineanu I, Schoffeniels E. 1996. Paradoxical sleep deprivation increases the content of glutamate and glutamine in rat cerebral cortex. Sleep 19: $65-71$.

Bjorness TE, Greene RW. 2009. Adenosine and sleep. Curr Neuropharmacol 7: $238-2345$.

Bliss TV, Lomo T. 1973. Long-lasting potentiation of synaptic transmission in the dentate area of the anaesthetized rabbit following stimulation of the perforant path. Am J Physiol 232: 331-356.

Born J, Wilhelm I. 2012. System consolidation of memory during sleep. Psychol Res 76: 192-203.

Born J, Rasch B, Gais S. 2006. Sleep to remember. Neuroscientist 12: 410-424.

Bourtchouladze R, Abel T, Berman N, Gordon R, Lapidus K, Kandel ER. 1998. Different training procedures for contextual memory in mice can recruit either one or two critical periods for memory consolidation that require protein synthesis and PKA. Learn Mem 5: 365-374.

Brundege JM, Dunwiddie TV. 1996. Modulation of excitatory synaptic transmission by adenosine released from single hippocampal pyramidal neurons. J Neurosci 16: 5603-5612.
Buchegger J, Fritsch R, Meier-Koll A, Riehle H. 1991. Does trampolining and anaerobic physical fitness affect sleep? Percept Mot Skills 73: 243-252.

Bueno OF, Lobo LL, Oliveira MG, Gugliano EB, Pomarico AC, Tufik S. 1994 Dissociated paradoxical sleep deprivation effects on inhibitory avoidance and conditioned fear. Physiol Behav 56: 775-779.

Buzsáki G. 1998. Memory consolidation during sleep: A neurophysiological perspective. I Sleep Res 7(Suppl 1): 17-23.

Buzsáki G, Leung LW, Vanderwolf CH. 1983. Cellular bases of hippocampal EEG in the behaving rat. Brain Res 287: 139-171.

Campbell IG, Guinan MJ, Horowitz JM. 2002. Sleep deprivation impairs long-term potentiation in rat hippocampal slices. J Neurophysiol 88: 1073-1076.

Chang H-M, Liao W-C, Sheu J-N, Chang C-C, Lan C-T, Mai F-D. 2012. Sleep deprivation impairs $\mathrm{Ca}^{2+}$ expression in the hippocampus: Ionic imaging analysis for cognitive deficiency with TOF-SIMS. Microsc Microanal 18: 425-435.

Chemelli RM, Willie JT, Sinton CM, Elmquist JK, Scammell T, Lee C, Richardson JA, Williams SC, Xiong Y, Kisanuki Y, et al. 1999. Narcolepsy in orexin knockout mice: Molecular genetics of sleep regulation. Cell 98: 437-451.

Chen C, Hardy M, Zhang J, LaHoste GJ, Bazan NG. 2006. Altered NMDA receptor trafficking contributes to sleep deprivation-induced hippocampal synaptic and cognitive impairments. Biochem Biophys Res Commun 340: 435-440.

Cheval H, Chagneau C, Levasseur G, Veyrac A, Faucon-Biguet N, Laroche S, Davis S. 2012. Distinctive features of Egr transcription factor regulation and DNA binding activity in CA1 of the hippocampus in synaptic plasticity and consolidation and reconsolidation of fear memory. Hippocampus 22: 631-642.

Cirelli C. 2002. How sleep deprivation affects gene expression in the brain: A review of recent findings. J Appl Physiol 92: 394-400.

Cirelli C, Tononi G. 2000. Gene expression in the brain across the sleepwaking cycle. Brain Res 885: 303-321.

Cirelli C, Faraguna U, Tononi G. 2006. Changes in brain gene expression after long-term sleep deprivation. J Neurochem 98: 1632-1645.

Conti B, Maier R, Barr AM, Morale MC, Lu X, Sanna PP, Bilbe G, Hoyer D, Bartfai T. 2007. Region-specific transcriptional changes following the three antidepressant treatments electro convulsive therapy, sleep deprivation and fluoxetine. Mol Psychiatry 12: 167-189.

Cortese BM, Mitchell TR, Galloway MP, Prevost KE, Fang J, Moore GJ, Uhde TW. 2010. Region-specific alteration in brain glutamate: Possible relationship to risk-taking behavior. Physiol Behav 99: $445-450$.

Cui Z, Wang H, Tan Y, Zaia KA, Zhang S, Tsien JZ. 2004. Inducible and reversible NR1 knockout reveals crucial role of the NMDA receptor in preserving remote memories in the brain. Neuron 41: 781-793.

Curie T, Mongrain V, Dorsaz S, Mang GM, Emmenegger Y, Franken P. 2013. Homeostatic and circadian contribution to EEG and molecular state variables of sleep regulation. Sleep 36: 311-323.

Dash MB, Douglas CL, Vyazovskiy VV, Cirelli C, Tononi G. 2009. Long-term homeostasis of extracellular glutamate in the rat cerebral cortex across sleep and waking states. J Neurosci Nurs 29: 620-629.

Datta S, Hobson JA. 2000. The rat as an experimental model for sleep neurophysiology. Behav Neurosci 114: 1239-1244.

Datta S, Maclean RR. 2007. Neurobiological mechanisms for the regulation of mammalian sleep-wake behavior: Reinterpretation of historical evidence and inclusion of contemporary cellular and molecular evidence. Neurosci Biobehav Rev 31: 775-824.

Datta S, O'Malley MW. 2013. Fear extinction memory consolidation requires potentiation of pontine-wave activity during REM sleep. J Neurosci 33: 4561-4569.

Datta S, Saha S, Prutzman SL, Mullins OJ, Mavanji V. 2005. Pontine-wave generator activation-dependent memory processing of avoidance learning involves the dorsal hippocampus in the rat. J Neurosci Res 80: $727-737$.

Denenberg VH, Desantis D, Waite S, Thoman EB. 1977. The effects of handling in infancy on behavioral states in the rabbit. Physiol Behav 18: $553-557$.

Diekelmann S, Born J. 2010. The memory function of sleep. Nat Rev Neurosci 11: 114-126.

Disbrow JK, Ruth JA. 1984. Differential glutamate release in brain regions of long sleep and short sleep mice. Alcohol 1: 201-203.

Doyon J, Penhune V, Ungerleider LG. 2003. Distinct contribution of the cortico-striatal and cortico-cerebellar systems to motor skill learning. Neuropsychologia 41: 252-262.

Dudai Y. 2004. The neurobiology of consolidations, or, how stable is the engram? Annu Rev Psychol 55: 51-86.

Durmer JS, Dinges DF. 2009. Neurocognitive consequences of sleep deprivation. Semin Neurol 29: 320-339.

Ego-Stengel V, Wilson MA. 2010. Disruption of ripple-associated hippocampal activity during rest impairs spatial learning in the rat. Hippocampus 20: 1-10. 
Elmenhorst D, Meyer PT, Winz OH, Matusch A, Ermert J, Coenen HH, Basheer R, Haas HL, Zilles K, Bauer A. 2007. Sleep deprivation increases A1 adenosine receptor binding in the human brain: A positron emission tomography study. J Neurosci 27: 2410-2415.

Engeda J, Mezuk B, Ratliff S, Ning Y. 2013. Association between duration and quality of sleep and the risk of pre-diabetes: Evidence from NHANES. Diabet Med 30: 676-680

Enslen H, Sun P, Brickey D, Soderling SH, Klamo E, Soderling TR. 1994. Characterization of $\mathrm{Ca}^{2+} /$ calmodulin-dependent protein kinase IV. Role in transcriptional regulation. J Biol Chem 269: 15520-15527.

Fishbein W. 1971. Disruptive effects of rapid eye movements sleep deprivation on long-term memory. Physiol Behav 6: 279-282.

Florian C, Vecsey CG, Halassa MM, Haydon PG, Abel T. 2011. Astrocyte-derived adenosine and A1 receptor activity contribute to sleep loss-induced deficits in hippocampal synaptic plasticity and memory in mice. J Neurosci 31: 6956-6962.

Ford DE. 1989. Epidemiologic study of sleep disturbances and psychiatric disorders. An opportunity for prevention? JAMA 262: 1479.

Fowler MJ, Sullivan MJ, Ekstrand BR. 1973. Sleep and memory. Science 179: 302-304.

Franken P, Dijk DJ, Tobler I, Borbély AA. 1991a. Sleep deprivation in rats: Effects on EEG power spectra, vigilance states, and cortical temperature. Am J Physiol 261: R198-R208.

Franken P, Tobler I, Borbély A. 1991b. Sleep homeostasis in the rat: Simulation of the time course of EEG slow-wave activity. Neurosci Lett 130: $141-144$.

Frankland PW, O'Brien C, Ohno M, Kirkwood A, Silva AJ. 2001. $\alpha$-CaMKII-dependent plasticity in the cortex is required for permanent memory. Nature 411: 309-313.

Frankland PW, Bontempi B, Talton LE, Kaczmarek L, Silva AJ. 2004. The involvement of the anterior cingulate cortex in remote contextual fear memory. Science 304: 881-883.

Fredholm BB, Bättig K, Holmén J, Nehlig A, Zvartau EE. 1999. Actions of caffeine in the brain with special reference to factors that contribute to its widespread use. Pharmacol Rev 51: 83-133.

Fredholm BB, Chen J-F, Cunha RA, Svenningsson P, Vaugeois J-M. 2005. Adenosine and brain function. Int Rev Neurobiol 63: 191-270.

Gais S, Born J. 2004. Declarative memory consolidation: Mechanisms acting during human sleep. Learn Mem 11: 679-685.

Gais S, Mölle M, Helms K, Born J. 2002. Learning-dependent increases in sleep spindle density. J Neurosci 22: 6830-6834.

Gais S, Lucas B, Born J. 2006. Sleep after learning aids memory recall. Learn Mem 13: 259-262.

Gais S, Albouy G, Boly M, Dang-Vu TT, Darsaud A, Desseilles M, Rauchs G, Schabus M, Sterpenich V, Vandewalle G, et al. 2007. Sleep transforms the cerebral trace of declarative memories. Proc Natl Acad Sci 104: $18778-18783$

Gerrard P, Malcolm R. 2007. Mechanisms of modafinil: A review of current research. Neuropsychiatr Dis Treat 3: 349-364.

Gillin JC. 1998. Are sleep disturbances risk factors for anxiety, depressive and addictive disorders? Acta Psychiatr Scand 98: 39-43.

Girardeau G, Benchenane K, Wiener SI, Buzsáki G, Zugaro MB. 2009. Selective suppression of hippocampal ripples impairs spatial memory. Nat Neurosci 12: 1222-1223.

Giuditta A, Ambrosini MV, Montagnese P, Mandile P, Cotugno M, Zucconi GG, Vescia S. 1995. The sequential hypothesis of the function of sleep. Behav Brain Res 69: 157-166.

Goerke M, Cohrs S, Rodenbeck A, Grittner U, Sommer W, Kunz D. 2013. Declarative memory consolidation during the first night in a sleep lab: The role of REM sleep and cortisol. Psychoneuroendocrinology 38: $1102-1111$.

Grassi Zucconi G, Cipriani S, Balgkouranidou I, Scattoni R. 2006. “One night" sleep deprivation stimulates hippocampal neurogenesis. Brain Res Bull 69: 375-381.

Graves L, Pack A, Abel T. 2001. Sleep and memory: A molecular perspective. Trends Neurosci 24: 237-243.

Graves LA, Heller EA, Pack AI, Abel T. 2003. Sleep deprivation selectively impairs memory consolidation for contextual fear conditioning. Learn Mem 10: $168-176$.

Grecksch G, Matthies H. 1980. Two sensitive periods for the amnesic effect of anisomycin. Pharmacol Biochem Behav 12: 663-665.

Greenstein YJ, Pavlides C, Winson J. 1988. Long-term potentiation in the dentate gyrus is preferentially induced at theta rhythm periodicity. Brain Res 438: 331-334.

Guzman-Marin R, Ying Z, Suntsova N, Methippara M, Bashir T, Szymusiak R, Gomez-Pinilla F, McGinty D. 2006. Suppression of hippocampal plasticity-related gene expression by sleep deprivation in rats. J Physiol 575: 807-819.

Haas HL, Selbach O. 2000. Functions of neuronal adenosine receptors. N-S Arch Pharmakol 362: 375-381.

Hagewoud R, Havekes R, Novati A, Keijser JN, Van der Zee EA, Meerlo P. 2010a. Sleep deprivation impairs spatial working memory and reduces hippocampal AMPA receptor phosphorylation. J Sleep Res 19: $280-288$.

Hagewoud R, Havekes R, Tiba P, Novati A, Hogenelst K, Weinreder P, Van der Zee E, Meerlo P. 2010b. Coping with sleep deprivation: Shifts in regional brain activity and learning strategy. Sleep 33: 1465-1473.

Hagewoud R, Whitcomb SN, Heeringa AN, Havekes R, Koolhaas JM, Meerlo P. 2010c. A time for learning and a time for sleep: The effect of sleep deprivation on contextual fear conditioning at different times of the day. Sleep 33: 1315-1322.

Halassa MM, Florian C, Fellin T, Munoz JR, Lee SY, Abel T, Haydon PG, Frank MG. 2009. Astrocytic modulation of sleep homeostasis and cognitive consequences of sleep loss. Neuron 61: 213-219.

Hargus NJ, Bertram EH, Patel MK. 2009. Adenosine A1 receptors presynaptically modulate excitatory synaptic input onto subiculum neurons. Brain Res 1280: 60-68.

Havekes R, Vecsey CG, Abel T. 2012. The impact of sleep deprivation on neuronal and glial signaling pathways important for memory and synaptic plasticity. Cell Signal 24: 1251-1260.

Hellman K, Abel T. 2007. Fear conditioning increases NREM sleep. Behav Neurosci 121: 310-323.

Hellman K, Hernandez P, Park A, Abel T. 2010. Genetic evidence for a role for protein kinase A in the maintenance of sleep and thalamocortical oscillations. Sleep 33: 19-28.

Hendricks JC, Williams JA, Panckeri K, Kirk D, Tello M, Yin JC, Sehgal A. 2001. A non-circadian role for cAMP signaling and CREB activity in Drosophila rest homeostasis. Nat Neurosci 4: 1108-1115.

Hennevin E, Hars B, Maho C, Bloch V. 1995. Processing of learned information in paradoxical sleep: Relevance for memory. Behav Brain Res 69: $125-135$.

Hernandez PJ, Abel T. 2011. A molecular basis for interactions between sleep and memory. Sleep Med Clin 6: 71-84.

Hirotsu C, Tufik S, Bergamaschi CT, Tenorio NM, Araujo P, Andersen ML. 2010. Sleep pattern in an experimental model of chronic kidney disease. Am J Physiol Renal Physiol 299: F1379-F1388.

Hobson J, Steriade M. 2011. Comprehensive physiology (ed. Terjung R), John Wiley \& Sons, Inc., Hoboken, NJ.

Huber R, Ghilardi MF, Massimini M, Tononi G. 2004. Local sleep and learning. Nature 430: $78-81$.

Huston J, Haas H, Boix F, Pfister M, Decking U, Schrader J, Schwarting R. 1996. Extracellular adenosine levels in neostriatum and hippocampus during rest and activity periods of rats. Neuroscience 73: 99-107.

Igaz LM, Vianna MRM, Medina JH, Izquierdo I. 2002. Two time periods of hippocampal mRNA synthesis are required for memory consolidation of fear-motivated learning. I Neurosci 22: 6781-6789.

Igaz LM, Bekinschtein P, Vianna MMR, Izquierdo I, Medina JH. 2004. Gene expression during memory formation. Neurotox Res 6: 189-204.

Ishikawa A, Kanayama Y, Matsumura H, Tsuchimochi H, Ishida Y, Nakamura S. 2006. Selective rapid eye movement sleep deprivation impairs the maintenance of long-term potentiation in the rat hippocampus. Eur J Neurosci 24: 243-248.

Jasper HH, Khan RT, Elliot KA. 1965. Amino acids released from the cerebral cortex in relation to its state of activation. Science 147: 1448-1449.

Jenkins JG, Dallenbach K. 1924. Obliviscence during sleep and waking. Am J Physiol 35: 605-612.

Ji D, Wilson MA. 2007. Coordinated memory replay in the visual cortex and hippocampus during sleep. Nat Neurosci 10: 100-107.

John J, Wu M-F, Boehmer LN, Siegel JM. 2004. Cataplexy-active neurons in the hypothalamus: Implications for the role of histamine in sleep and waking behavior. Neuron 42: 619-634.

Jouvet M. 1962. Research on the neural structures and responsible mechanisms in different phases of physiological sleep. Arch Ital Biol 100: $125-206$.

Kamphuis J, Meerlo P, Koolhaas JM, Lancel M. 2012. Poor sleep as a potential causal factor in aggression and violence. Sleep Med 13: 327-334.

Kapur VK, Redline S, Nieto FJ, Young TB, Newman AB, Henderson JA. 2002. The relationship between chronically disrupted sleep and healthcare use. Sleep 25: 289-296.

Klemm WR. 1976. Hippocampal EEG and information processing: A special role for theta rhythm. Prog Neurobiol 7: 197-214.

Klimesch W, Doppelmayr M, Yonelinas A, Kroll NE, Lazzara M, Röhm D, Gruber W. 2001. Theta synchronization during episodic retrieval: Neural correlates of conscious awareness. Cogn Brain Res 12: 33-38

Knutson KL, Van Cauter E. 2008. Associations between sleep loss and increased risk of obesity and diabetes. Ann N Y Acad Sci 1129: 287-304.

Kopp C, Longordo F, Nicholson JR, Lüthi A. 2006. Insufficient sleep reversibly alters bidirectional synaptic plasticity and NMDA receptor function. J Neurosci Nurs 26: 12456-12465.

Lecas J-C. 1976. Changes in paradoxical sleep accompanying instrumental learning in the cat. Neurosci Lett 3: 349-355.

Leconte P, Hennevin E, Bloch V. 1974. Duration of paradoxical sleep necessary for the acquisition of conditioned avoidance in the rat. Physiol Behav 13: 675-681. 
LeDoux JE. 2000. Emotion circuits in the brain. Annu Rev Neurosci 23 : $155-184$.

Ledoux L, Sastre JP, Buda C, Luppi PH, Jouvet M. 1996. Alterations in c-fos expression after different experimental procedures of sleep deprivation in the cat. Brain Res 735: 108-118.

Lee AK, Wilson MA. 2002. Memory of sequential experience in the hippocampus during slow wave sleep. Neuron 36: 1183-1194.

Linden E, Bern D, Fishbein W. 1975. Retrograde amnesia: Prolonging the fixation phase of memory consolidation by paradoxical sleep deprivation. Physiol Behav 14: 409-412.

Longordo F, Kopp C, Mishina M, Luján R, Lüthi A. 2009. NR2A at CA1 synapses is obligatory for the susceptibility of hippocampal plasticity to sleep loss. J Neurosci Nurs 29: 9026-9041.

Lopez J, Roffwarg HP, Dreher A, Bissette G, Karolewicz B, Shaffery JP. 2008. Rapid eye movement sleep deprivation decreases long-term potentiation stability and affects some glutamatergic signaling proteins during hippocampal development. Neuroscience 153: 44-53.

Lopez-Rodriguez F, Medina-Ceja L, Wilson CL, Jhung D, MoralesVillagran A. 2007. Changes in extracellular glutamate levels in rat orbitofrontal cortex during sleep and wakefulness. Arch Med Res 38: $52-55$.

Luo J, Phan TX, Yang Y, Garelick MG, Storm DR. 2013. Increases in cAMP, MAPK activity, and CREB phosphorylation during REM sleep: Implications for REM sleep and memory consolidation. J Neurosci 33: 6460-6468.

Machida M, Yang L, Wellman LL, Sanford LD. 2013. Effects of stressor predictability on escape learning and sleep in mice. Sleep 36: 421-430.

Mackiewicz M, Zimmerman JE, Shockley KR, Churchill Ga, Pack AI. 2009. What are microarrays teaching us about sleep? Trends Mol Med 15: $79-87$.

Mandai O, Guerrien A, Sockeel P, Dujardin K, Leconte P. 1989. REM sleep modifications following a Morse code learning session in humans. Physiol Behav 46: 639-642.

Marks CA, Wayner MJ. 2005. Effects of sleep disruption on rat dentate granule cell LTP in vivo. Brain Res Bull 66: 114-119.

Marshall L, Born J. 2007. The contribution of sleep to hippocampusdependent memory consolidation. Trends Cogn Sci 11: 442-450.

Marshall L, Helgadóttir H, Mölle M, Born J. 2006. Boosting slow oscillations during sleep potentiates memory. Nature 444: 610-613.

Massimini M, Ferrarelli F, Esser SK, Riedner BA, Huber R, Murphy M, Peterson MJ, Tononi G. 2007. Triggering sleep slow waves by transcranial magnetic stimulation. Proc Natl Acad Sci 104: 8496-8501.

Matthews RP, Guthrie CR, Wailes LM, Zhao X, Means AR, McKnight GS. 1994. Calcium/calmodulin-dependent protein kinase types II and IV differentially regulate CREB-dependent gene expression. Mol Cell Biol 14: $6107-6116$

Maviel T, Durkin TP, Menzaghi F, Bontempi B. 2004. Sites of neocortical reorganization critical for remote spatial memory. Science 305: 96-99.

McDermott CM, LaHoste GJ, Chen C, Musto A, Bazan NG, Magee JC. 2003. Sleep deprivation causes behavioral, synaptic, and membrane excitability alterations in hippocampal neurons. J Neurosci Nurs 23: 9687-9695.

McDermott CM, Hardy MN, Bazan NG, Magee JC. 2006. Sleep deprivation-induced alterations in excitatory synaptic transmission in the CA1 region of the rat hippocampus. J Physiol 570: 553-565.

Mednick SC, McDevitt EA, Walsh JK, Wamsley E, Paulus M, Kanady JC, Drummond SPA. 2013. The critical role of sleep spindles in hippocampal-dependent memory: A pharmacology study. J Neurosci 33: 4494-4504.

Menz MM, Rihm JS, Salari N, Born J, Kalisch R, Pape HC, Marshall L, Büchel C. 2013. The role of sleep and sleep deprivation in consolidating fear memories. NeuroImage 75: 87-96.

Mölle M, Born J. 2011. Slow oscillations orchestrating fast oscillations and memory consolidation. Prog Brain Res 193: 93-110.

Mölle M, Bergmann TO, Marshall L, Born J. 2011. Fast and slow spindles during the sleep slow oscillation: Disparate coalescence and engagement in memory processing. Sleep 34: 1411-1421.

Moreira K, Ferreira T, Hipolide D, Fornari R, Tufik S, Oliveira M. 2010. Modafinil prevents inhibitory avoidance memory deficit induced by sleep deprivation in rats. Sleep 33: 990-993.

Morris RGM, Garrud P, Rawlins JNP, O'Keefe J. 1982. Place navigation impaired in rats with hippocampal lesions. Nature 297: 681-683.

Mukherjee D, Kaushik MK, Jaryal AK, Kumar VM, Mallick HN. 2012. Glutamate microinjection in the medial septum of rats decrease paradoxical sleep and increases slow wave sleep. Neuroreport 23: 451-456.

Najafian J, Mohamadifard N, Siadat ZD, Sadri G, Rahmati MR. 2013. Association between sleep duration and diabetes mellitus: Isfahan Healthy Heart Program. Niger J Clin Pract 16: 59-62.

Ngo H-VV, Martinetz T, Born J, Mölle M. 2013. Auditory closed-loop stimulation of the sleep slow oscillation enhances memory. Neuron $\mathbf{7 8}$ $545-553$.
Nokia MS, Mikkonen JE, Penttonen M, Wikgren J. 2012. Disrupting neural activity related to awake-state sharp wave-ripple complexes prevents hippocampal learning. Front Behav Neurosci 6: 84.

O'Keefe J, Burgess N. 1999. $\theta$ activity, virtual navigation and the human hippocampus. Trends Cogn Sci 3: 403-406.

Oliveira MG, Bueno OF, Pomarico AC, Gugliano EB. 1997. Strategies used by hippocampal- and caudate-putamen-lesioned rats in a learning task. Neurobiol Learn Mem 68: 32-41.

Oudiette D, Antony JW, Creery JD, Paller KA. 2013. The role of memory reactivation during wakefulness and sleep in determining which memories endure. J Neurosci 33: 6672-6678.

Palagini L, Bruno RM, Gemignani A, Baglioni C, Ghiadoni L, Riemann D. 2013. Sleep loss and hypertension: A systematic review. Curr Pharm Des 19: $2409-2419$.

Palchykova S, Winsky-Sommerer R, Meerlo P, Dürr R, Tobler I. 2006. Sleep deprivation impairs object recognition in mice. Neurobiol Learn Mem 85: $263-271$.

Palchykova S, Winsky-Sommerer R, Tobler I. 2009. Sleep deprivation in the dark period does not impair memory in OF1 mice. Chronobiol Int 26: 682-696.

Park HJ, Kang WS, Paik JW, Kim JW. 2012. Effect of valproic acid through regulation of NMDA receptor-ERK signaling in sleep deprivation rats. J Mol Neurosci 47: 554-558.

Pavlides C, Winson J. 1989. Influences of hippocampal place cell firing in the awake state on the activity of these cells during subsequent sleep episodes. J Neurosci Nurs 9: 2907-2918.

Peyrache A, Khamassi M, Benchenane K, Wiener SI, Battaglia FP. 2009. Replay of rule-learning related neural patterns in the prefrontal cortex during sleep. Nat Neurosci 12: 919-926.

Pinho N, Moreira KM, Hipolide DC, Sinigaglia-Coimbra R, Ferreira TL, Nobrega JN, Tufik S, Oliveira MGM. 2013. Sleep deprivation alters phosphorylated CREB levels in the amygdala: Relationship with performance in a fear conditioning task. Behav Brain Res 236: 221-224.

Plihal W, Born J. 1997. Effects of early and late nocturnal sleep on declarative and procedural memory. J Cogn Neurosci 9: 534-547.

Plihal W, Born J. 1999. Effects of early and late nocturnal sleep on priming and spatial memory. Psychophysiology 36: 571-582.

Poldrack RA, Clark J, Paré-Blagoev EJ, Shohamy D, Creso Moyano J, Myers C, Gluck MA. 2001. Interactive memory systems in the human brain. Nature 414: 546-550.

Porkka-Heiskanen T. 1997. Adenosine: A mediator of the sleep-inducing effects of prolonged wakefulness. Science 276: 1265-1268.

Porkka-Heiskanen T, Kalinchuk AV. 2011. Adenosine, energy metabolism and sleep homeostasis. Sleep Med Rev 15: 123-135.

Porter NM, Bohannon JH, Curran-Rauhut M, Buechel HM, Dowling ALS, Brewer LD, Popovic J, Thibault V, Kraner SD, Chen KC, et al. 2012. Hippocampal CA1 transcriptional profile of sleep deprivation: Relation to aging and stress. PloS One 7: e40128.

Rajaratnam SM, Arendt J. 2001. Health in a 24-h society. Lancet 358: 999-1005.

Rasch B, Büchel C, Gais S, Born J. 2007. Odor cues during slow-wave sleep prompt declarative memory consolidation. Science 315: 1426-1429.

Rasch B, Pommer J, Diekelmann S, Born J. 2009. Pharmacological REM sleep suppression paradoxically improves rather than impairs skill memory. Nat Neurosci 12: 396-397.

Ravassard P, Pachoud B, Comte J-C, Mejia-Perez C, Scoté-Blachon C, Gay N, Claustrat B, Touret M, Luppi P-H, Salin PA. 2009. Paradoxical (REM) sleep deprivation causes a large and rapidly reversible decrease in long-term potentiation, synaptic transmission, glutamate receptor protein levels, and ERK/MAPK activation in the dorsal hippocampus. Sleep 32: 227-240.

Rechtschaffen A, Kales A, ed. 1968. A manual of standardized terminology, techniques and scoring system for sleep stages of human subjects. Brain Information Service, Brain Research Institute, UCLA, Los Angeles, CA.

Roberson ED, Sweatt JD. 1999. A biochemical blueprint for long-term memory. Learn Mem 6: 381-388.

Roberson ED, English JD, Adams JP, Selcher JC, Kondratick C, Sweatt JD. 1999. The mitogen-activated protein kinase cascade couples PKA and PKC to cAMP response element binding protein phosphorylation in area CA1 of hippocampus. J Neurosci 19: 4337-4348.

Romcy-Pereira R, Pavlides C. 2004. Distinct modulatory effects of sleep on the maintenance of hippocampal and medial prefrontal cortex LTP. Eur I Neurosci 20: 3453-3462.

Rudoy JD, Voss JL, Westerberg CE, Paller KA. 2009. Strengthening individual memories by reactivating them during sleep. Science 326: 1079.

Ruskin DN, LaHoste GJ. 2009. Reduced-volume cues effectively support fear conditioning despite sleep deprivation. Physiol Behav 96: 64-66.

Ruskin DN, Liu C, Dunn KE, Bazan NG, LaHoste GJ. 2004. Sleep deprivation impairs hippocampus-mediated contextual learning but not amygdala-mediated cued learning in rats. Eur J Neurosci 19: 3121-3124. 
Sagales T, Domino EF. 1973. Effects of stress and REM sleep deprivation on the patterns of avoidance learning and brain acetylcholine in the mouse. Psychopharmacologia 29: 307-315.

Sanford LD, Yang L, Wellman LL, Liu X, Tang X. 2010. Differential effects of controllable and uncontrollable footshock stress on sleep in mice. Sleep 33: $621-630$.

Scammell TE, Estabrooke IV, McCarthy MT, Chemelli RM, Yanagisawa M, Miller MS, Saper CB. 2000. Hypothalamic arousal regions are activated during modafinil-induced wakefulness. J Neurosci 20: 8620-8628.

Schendan HE, Searl MM, Melrose RJ, Stern CE. 2003. An FMRI study of the role of the medial temporal lobe in implicit and explicit sequence learning. Neuron 37: 1013-1025.

Schmitt WB, Sprengel R, Mack V, Draft RW, Seeburg PH, Deacon RMJ, Rawlins JNP, Bannerman DM. 2005. Restoration of spatial working memory by genetic rescue of GluR-A-deficient mice. Nat Neurosci $\mathbf{8}$ : $270-272$.

Seibt J, Dumoulin MC, Aton SJ, Coleman T, Watson A, Naidoo N, Frank MG. 2012. Protein synthesis during sleep consolidates cortical plasticity in vivo. Curr Biol 22: 676-682.

Siegel JM. 2001. The REM sleep-memory consolidation hypothesis. Science 294: $1058-1063$.

Smith C. 1985. Sleep states and learning: A review of the animal literature. Neurosci Behav Rev 9: 157-168.

Smith C. 2001. Sleep states and memory processes in humans: Procedural versus declarative memory systems. Sleep Med Rev 5: 491-506.

Smith C, Lapp L. 1991. Increases in number of REMS and REM density in humans following an intensive learning period. Sleep 14: 325-330.

Smith C, Rose GM. 1996. Evidence for a paradoxical sleep window for place learning in the Morris water maze. Physiol Behav 59: 93-97.

Smith C, Rose GM. 1997. Posttraining paradoxical sleep in rats is increased after spatial learning in the Morris water maze. Behav Neurosci 111: 1197-1204.

Smith C, Smith D. 2003. Ingestion of ethanol just prior to sleep onset impairs memory for procedural but not declarative tasks. Sleep 26: $185-191$.

Squire LR, Knowlton B, Musen G. 1993. The structure and organization of memory. Annu Rev Psychol 44: 453-495.

Steriade M, McCormick DA, Sejnowski TJ. 1993a. Thalamocortical oscillations in the sleeping and aroused brain. Science 262: 679-685.

Steriade M, Nunez A, Amzica F. 1993b. Intracellular analysis of relations between the slow $(<1 \mathrm{~Hz})$ neocortical oscillation and other sleep rhythms of the electroencephalogram. J Neurosci 13: 3266-3283.

Stickgold R. 1998. Sleep: Off-line memory reprocessing. Trends Cogn Sci 2: $484-492$.

Stickgold R, Walker MP. 2013. Sleep-dependent memory triage: Evolving generalization through selective processing. Nat Neurosci 16: 139-145.

Stickgold R, Whidbee D, Schirmer B, Patel V, Hobson JA. 2000. Visual discrimination task improvement: A multi-step process occurring during sleep. J Cogn Neurosci 12: 246-254.

Stickgold R, Hobson JA, Fosse R, Fosse M. 2001. Sleep, learning, and dreams Off-line memory reprocessing. Science 294: 1052-1057.

Strine TW, Chapman DP. 2005. Associations of frequent sleep insufficiency with health-related quality of life and health behaviors. Sleep Med 6: 23-27.

Tadavarty R, Kaan TKY, Sastry BR. 2009. Long-term depression of excitatory synaptic transmission in rat hippocampal CA1 neurons following sleep-deprivation. Exp Neurol 216: 239-242.

Tadavarty R, Rajput PS, Wong JM, Kumar U, Sastry BR. 2011. Sleep-deprivation induces changes in $\mathrm{GABA}_{\mathrm{B}}$ and mGlu receptor expression and has consequences for synaptic long-term depression. PloS One 6: e24933.

Taishi P, Sanchez C, Wang Y, Fang J, Harding JW, Krueger JM. 2001. Conditions that affect sleep alter the expression of molecules associated with synaptic plasticity. Am J Physiol Regul Integr Comp Physiol 281: R839-R845.

Tamaki M, Matsuoka T, Nittono H, Hori T. 2008. Fast sleep spindle (13-15 $\mathrm{Hz}$ ) activity correlates with sleep-dependent improvement in visuomotor performance. Sleep 31: 204-211.

Tamaki M, Matsuoka T, Nittono H, Hori T. 2009. Activation of fast sleep spindles at the premotor cortex and parietal areas contributes to motor learning: A study using sLORETA. Clin Neurophysiol 120: 878-886.

Tartar JL, Ward CP, McKenna JT, Thakkar M, Arrigoni E, McCarley RW, Brown RE, Strecker RE. 2006. Hippocampal synaptic plasticity and spatial learning are impaired in a rat model of sleep fragmentation. Eur J Neurosci 23: 2739-2748.

Taxidis J, Mizuseki K, Mason R, Owen MR. 2013. Influence of slow oscillation on hippocampal activity and ripples through cortico-hippocampal synaptic interactions, analyzed by a cortical-CA3-CA1 network model. Front Comput Neurosci 7: 3.

Tononi G, Cirelli C. 2001. Modulation of brain gene expression during sleep and wakefulness: A review of recent findings. Neuropsychopharmacology 25: S28-S35.
Trachsel L, Tobler I, Achermann P, Borbély AA. 1991. Sleep continuity and the REM-nonREM cycle in the rat under baseline conditions and after sleep deprivation. Physiol Behav 49: 575-580.

Trifilieff P, Herry C, Vanhoutte P, Caboche J, Desmedt A, Riedel G, Mons N, Micheau J. 2006. Foreground contextual fear memory consolidation requires two independent phases of hippocampal ERK/CREB activation. Learn Mem 13: 349-358.

Van Dongen HPA, Maislin G, Mullington JM, Dinges DF. 2003. The cumulative cost of additional wakefulness: Dose-response effects on neurobehavioral functions and sleep physiology from chronic sleep restriction and total sleep deprivation. Sleep 26: 117-126.

Van Dongen EV, Takashima A, Barth M, Zapp J, Schad LR, Paller KA, Fernández G. 2012. Memory stabilization with targeted reactivation during human slow-wave sleep. Proc Natl Acad Sci 109: 10575-10580.

Vecsey CG, Baillie GS, Jaganath D, Havekes R, Daniels A, Wimmer M, Huang T, Brown KM, Li X-Y, Descalzi G, et al. 2009. Sleep deprivation impairs cAMP signalling in the hippocampus. Nature 461: 1122-1125.

Vecsey CG, Peixoto L, Choi JHK, Wimmer M, Jaganath D, Hernandez PJ, Blackwell J, Meda K, Park AJ, Hannenhalli S, et al. 2012. Genomic analysis of sleep deprivation reveals translational regulation in the hippocampus. Physiol Genomics 44: 981-991.

Vijayan VK. 2012. Morbidities associated with obstructive sleep apnea Expert Rev Respir Med 6: 557-566.

Vyazovskiy VV, Cirelli C, Pfister-Genskow M, Faraguna U, Tononi G. 2008. Molecular and electrophysiological evidence for net synaptic potentiation in wake and depression in sleep. Nat Neurosci 11: 200-208.

Vyazovskiy VV, Faraguna U, Cirelli C, Tononi G. 2009. Triggering slow waves during NREM sleep in the rat by intracortical electrical stimulation: Effects of sleep/wake history and background activity. $J$ Neurophysiol 101: 1921-1931.

Wagner U. 2002. Changes in emotional responses to aversive pictures across periods rich in slow-wave sleep versus rapid eye movement sleep. Adv Psychosom Med 64: 627-634.

Wagner U, Gais S, Born J. 2001. Emotional memory formation is enhanced across sleep intervals with high amounts of rapid eye movement sleep. Learn Mem 8: 112-119.

Wagner U, Hallschmid M, Verleger R, Born J. 2003. Signs of REM sleep dependent enhancement of implicit face memory: A repetition priming study. Biol Psychol 62: 197-210.

Walker MP, Brakefield T, Morgan A, Hobson JA, Stickgold R. 2002. Practice with sleep makes perfect: Sleep-dependent motor skill learning. Neuron 35: $205-211$.

Walker MP, Brakefield T, Seidman J, Morgan A, Hobson JA, Stickgold R. 2003. Sleep and the time course of motor skill learning. Learn Mem 10: $275-284$

Wang S-X, Li Q-S. 2002. Effects of sleep deprivation on $\gamma$-amino-butyric acid and glutamate contents in rat brain. Acad J First Med Coll PLA 22: 888-890.

Wang H, Liu Y, Briesemann M, Yan J. 2010. Computational analysis of gene regulation in animal sleep deprivation. Physiol Genomics 42: 427-436.

Watts A, Gritton HJ, Sweigart J, Poe GR. 2012. Antidepressant suppression of non-REM sleep spindles and REM sleep impairs hippocampusdependent learning while augmenting striatum-dependent learning. $J$ Neurosci 32: 13411-13420.

Whitlock JR, Heynen AJ, Shuler MG, Bear MF. 2006. Learning induces long-term potentiation in the hippocampus. Science 313: 1093-1097.

Wilson M, McNaughton B. 1994. Reactivation of hippocampal ensemble memories during sleep. Science 265: 676-679.

Wiltgen BJ, Brown RAM, Talton LE, Silva AJ. 2004. New circuits for old memories: The role of the neocortex in consolidation. Neuron 44: $101-108$.

Wu MN, Ho K, Crocker A, Yue Z, Koh K, Sehgal A. 2009. The effects of caffeine on sleep in Drosophila require PKA activity, but not the adenosine receptor. J Neurosci 29: 11029-11037.

Xia Z, Storm DR. 2012. Role of signal transduction crosstalk between adenylyl cyclase and MAP kinase in hippocampus-dependent memory. Learn Mem 19: 369-374.

Xu Y, Ku B, Tie L, Yao H, Jiang W, Ma X, Li X. 2006. Curcumin reverses the effects of chronic stress on behavior, the HPA axis, BDNF expression and phosphorylation of CREB. Brain Res 1122: 56-64.

Yang Z, Zhang W, Wang M, Ruan D, Chen J. 2012. Effects of daytime, night and sleep pressure on long-term depression in the hippocampus in vivo. Neurosci Lett 511: 106-109.

Yaroush R, Sullivan MJ, Ekstrand BR. 1971. Effect of sleep on memory. II. Differential effect of the first and second half of the night. J Exp Psychol 88: $361-366$

Zhao Z, Huang L, Wu H, Li Y, Zhang L, Yin Y, Xiang Z, Zhao Z. 2010. Neuropeptide $S$ mitigates spatial memory impairment induced by rapid eye movement sleep deprivation in rats. Neuroreport 21: 623-628.

Received April 30, 2013; accepted in revised form July 29, 2013. 


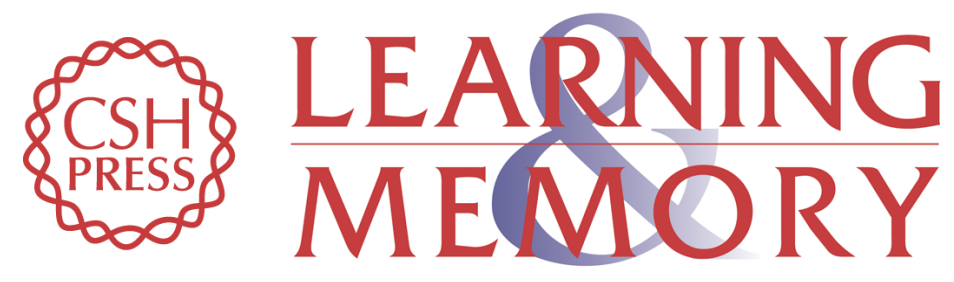

\section{The impact of sleep loss on hippocampal function}

Toni-Moi Prince and Ted Abel

Learn. Mem. 2013, 20:

Access the most recent version at doi:10.1101//m.031674.113

References This article cites 221 articles, 43 of which can be accessed free at: http://learnmem.cshlp.org/content/20/10/558.full.html\#ref-list-1

Creative This article is distributed exclusively by Cold Spring Harbor Laboratory Press for the Commons first 12 months after the full-issue publication date (see

License http://learnmem.cshlp.org/site/misc/terms.xhtml). After 12 months, it is available under a Creative Commons License (Attribution-NonCommercial 3.0 Unported), as described at http://creativecommons.org/licenses/by-nc/3.0/.

Email Alerting Receive free email alerts when new articles cite this article - sign up in the box at the Service top right corner of the article or click here. 